\title{
THE PEDI WOMAN'S EXPERIENCES OF CHILDBIRTH AND EARLY PARENTHOOD: A SUMMARY OF MAJOR FINDINGS
}

\author{
Beverley Chalmers
}

In recent years researchers have addressed themselves to the contrast between White's and Black's views on health and illness in Southern Africa (Barker, 1973; Cheetham and Griffiths, 1982; Gelf and 1977, 1980; Gumede, 1974, 1978; Manganyi, 1974; Menkazana, 1979; Munyaradzi, 1975). In essence, it appears that Black and White views regarding illness arise from two rather different standpoints. Empirical Western medicine has been concerned with the identification and manipulation of observable aetiological factors underlying illnesses. As this approach is concerned with the disease process itself the broad social and psychological concerns of the person with the disease have frequently been ignored (Cheetham and Griffiths, 1982). Relative to the history of medicine, it is only in recent decades that a more inclusive, holistic view of illness and health has been adopted by some (Lipowski, Lipsett and Whybrow, 1977). This holistic view takes account of the influences of social, psychological, cultural, religious, economic and behavioural factors in the aetiology and prognosis of disease.

In contrast to "high technology" medicine, the Black view of health and illness is set squarely into an holistic framework. To some extent this view overlaps with the move towards holistic medicine that has become evident in Western medicine. However, the Black view of illness goes even further towards viewing man as an integral part of his worldly environment. Not only are the psycho-social and physical aspects of his world influential in the aetiology and prognosis of his disease, but so too are the spiritual, magical or mystical aspects of the total ecology of relevance to health and disease. In fact, these extra-terrestrial forces are seen as primary agents in the causation of illness, even when the illness is directly observed as being caused by organic agents. In these situations the organic agent acts adversely on the individual in response to spiritual intervention. Within this framework, it becomes obvious that appeasement of ancestral or other spirits is an integral part of the process of remaining healthy. To this end individuals such as traditional healers who have the ability to communicate with the spirits are accorded high status in the community.

While Black views of illness incorporate a multivariate approach to the aetiology of illness, White philosophies traditionally tend to separate certain aspects from each other. In the middle ages based on a concept of mind-body dichotomy, man was divided into three aspects, mind, body

\section{Abstract}

Traditional Black views of health and illness are contrasted to those of Whites. In particular, customs, practices and attitudes to childbirth and early infant care amongst Blacks are outlined.

Within this framework, two interview protocols of approximately 170 items each, are described. These were designed to explore the urban and rural Pedi woman's knowledge, attitudes. beliefs and practices regarding childbirth and early infant care as influenced by her social and economic environment.

Practical issues concerning the use of these interview protocols are described. Major findings pertaining to aspects of the pre-natal, birth and post-natal experiences of women are reported. Possible implications of these findings are suggested.

\section{Opsomming}

Tradisionele opvattings van die Swart bevolking omtrent gesondheid en siekte word met dié van Blankes vergelyk. In besonder word na gebruike, praktyke en houdings ten opsigte van bevalling en vroeë kindersorg onder die Swart bevolking verwys.

Binne die raamwerk word twee onderhoudprotokols, wat elk ongeveer 170 items behels, beskryf. Die protokols is ontwerp om die landelike en stedelike Pedi-vrou se kennis, houdings, gelowe en gebruike met betrekking tot bevalling en kindersorg te ondersoek soos dit deur haar sosiale en ekonomiese omgewing beïnvloed word

Praktiese wenke omtrent die gebruik van die onderhoudprotokols word aan die hand gedoen. Die vernaamste bevindings oor aspekte van voorgeboortelike, bevallings- en nágeboortelike ervarings van vroue word aangegee. Daar word gewys op moontlike implikasies van hierdie bevindinge.

and spirit: Medicine was administered by 'bleeders' and 'bile examiners' and was concerned with man's physical welfare. Mind was attended to by the occult sciences such as magic and alchemy and the spirit was the concern of religion. Western civilization has tended to perpetuate this conception of man as a fragmented being rather than seeing him as an integrated whole. For instance today, physicians heal the body, psychiatrists and psychologists treat the mind and the clergy is still attendant on the scul. In times of illness in Southern Africa at least, the black man will approach the spirits to overcome physical or psychological ailments. The White man must appeal to his doctor, his psychologist if necessary and to his religious deity for help.

Pregnancy within the Black holistic framework of health

Traditional Black knowledge of the physical aspects of pregnancy and birth seems to be quite extensive. While some differences in knowledge of or practices concerned with birth are evident in the different tribal groups, many issues seem to have been commonly addressed. To a large extent, traditional practices concerning pregnancy and birth are congruent with a Western medical approach. However some practices do exist which by Western standards may be detrimental to the health of either the mother or her baby, e.g. routine repeated enemas in newborns to cleanse the baby (Brindley, 1985a) or blood letting of the vulva in the ante-partum mother to reduce oedema, or to minimize haemorrhage during delivery (Brindley, 1985a).

Details about birth practices in the various tribal groups are not readily available. Whether this is because these aspects of tribal life have not been regarded as important enough to document or whether it is because birth is a traditionally female experience from which men were excluded (and, by extension, male researchers) is not known. What follows is a summary of the major issues which have appeared in the literature. Where applicable practices peculiar to a particular tribal group have been specified as such. However, as Leedham (1985) indicates many of these practices are generalizable across groups.

\section{Pregnancy}

Amongst the Zulus at least, pregnancy is recognized by the cessation of menstruation, by enlargement and pigmentation of the breasts, by the presence of colostrum, by the appearance of food cravings and by chloasma (Gumede, 1978). In the same people, according to Larsen, Msane and Monkhe (1983) pregnancy is usually confirmed at between four and six months with the feeling of life (Brindley, 1985a). Gestation is calculated according to the lunar cycle. Delivery occurs during the four weeks 
following the completion of nine lunar cycles and calculation of these dates is fairly accurate (Gumede, 1978; Larsen et al, 1983).

Coitus is generally permitted during pregnancy and even encouraged in the early months to 'strengthen the embryo' (Brindley, 1983), but amongst Basuto, Pondo (Freedman, 1972) and Zulu (Larsen et al, 1983) at least it is restricted during the last few months. From a Western medical perspective the prohibition of intercourse during the later stages of pregnancy is beneficial as it results in a reduced incidence of chorio-amnionit is, and its associated complications. These include premature rupture of membranes, premature labour, increased incidence of abruptio placentae and increased perinatal mortality rate (Larsen et al, 1983). Further evidence supporting the benefits of prohibition of coitus during pregnancy in Blacks is provided by Ross, Macpherson, Naeye, Khatree and Wallace (1982). Ross al, (1982) report that the principle fence against coitus-linked infections high levels of antimicrobial activity in the amniotic fluid - is absent in most Durban Blacks possibly due to low levels of zinc, needed for such antimicrobial activity, in the diet.

During pregnancy the traditional healer may be consulted for medications, e.g. isihlambezo, which is believed to give quick easy confinements (Brindley, 1983; Gumede, 1978) to 'loosen the foetus in the womb' (Brindley, 1983) and to prevent oedema or the appearance of vernix on the newborn which may be regarded as a sign of inadequate continence of the husband during pregnancy (Brindley, 1985a; Larsen et al, 1983). There are numerous formulae for these medications, each 'nyanga' (traditional healer) preferring his own. In general they appear to be harmless (Larsen et al, 1983), although some questions as to their oxytocic effect have been posed. Mphahlele (1982) has reported that hongst the Pedi it was customary to reduce total dietary intake from the early stages of pregnancy so as to prevent large babies which according to their understanding would lead to difficult deliveries or disproportion. Considering that cephalo-pelvic disproportion is a common problem amongst Blacks (Stein and Mouton, 1979; Stewart, Cowan and Philpott, 1979) this traditional practice seems to be most insightful.

\footnotetext{
Labour

Women are encouraged to remain ambulant and active during the first stage of labour (Larsen et al, 1983). A squatting position is adopted for birth, with the heels supporting the perineum (Brindley, 1983; Gumede, 1978). Much moral and physical support is given during labour (Brindley, 1983,1985 b; Gumede, 1978) but only by trusted women. 'Isihlambezo' and a further herbal medicine, 'inembe', may be given to stimulate contractions in difficult deliveries (Brindley, 1985a). Fathers are not permitted to be present. The infant's mouth is cleared so that its voice is clear, (Brindley, 1985a) as it is delivered
}

(Gumede, 1978) and blood is milked from the placenta to the baby (Gumede, 1978). While Gumede (1978) and Brindley (1985a) report that amongst Zulus a knot is tied in the cord, Larsen et al (1983) report that the cord is not tied. Following delivery the placenta is buried (Gumede, 1978). According to Brindley (1983) all blood lost during the birth, in addition to the placenta or membranes are potential sources of witchcraft and must be buried after delivery, usually by the mother herself or by her mother-in-law. Only trusted women may handle these products of birth. Carelessness in this regard could enable a malicious person to use the substances to prevent the woman from conceiving again or even to cause the death of the mother or her baby. Men are 'weakened' by contact and association with the birth experience.

In cases of delayed placental delivery, the mother is required to blow into a calabash or bottle to facilitate bearing down (Gumede, 1978). If essential, a manual removal may be performed but only very experienced birth attendants will attempt this procedure (Brindley, 1983; Gumede, 1978; Larsen et al, 1983a). Placental delivery problems, in fact, provide traditional birth attendants with the greatest anxiety as they are least able to handle this aspect of delivery (Brindley, 1985a).

\section{Infant care}

The dangers of hypothermia are acknowledged, and a fire is usually made in the childbirth hut (Larsen et al, 1983). Following birth the infant is usually cleaned, covered in vaseline (Gumede, 1978; Gelfand, 1980) or fat (Brindley, 1985a) to make sure it will 'grow up very quickly' and wrapped warmly. To rid the infant of meconium - believed to be the blood swallowed by the infant (Gumede, 1978) - and to cleanse it, medicines are given to the baby or enemas are performed. According to Gumede (1978), amongst Zulus, the baby is put to the breast soon after birth while according to Larsen et al (1983) colostrum is viewed with revulsion and the first suckling is delayed until 12 to 24 hours after delivery. Colostrum in this case is expressed and discarded. Instead, babies are traditionally fed with the milk of a newly delivered cow. If this is not available, as is more often the case in recent times, the baby is fed a watery form of available porridge until the mother's 'real' milk comes in (Mazibuko, 1985). Medicinal powders made from prescribed parts of wild animals are also burned, while the infant is enveloped in the smoke to strengthen it (Brindley, 1985a).

This practice is continued today for babies that are born in hospital, after their return home (Brindley, 1985a).

In traditional births mild abnormalities of the baby are tolerated e.g. squints and birthmarks, but more severe problems such as cleft palate, hare-lips, hydrocephalus, spina bifida, are not allowed to survive. In addition multiple birth babies are usually killed, with the exception of twins, where one baby was allowed to live (Gumede, 1978).

According to Larsen et al (1983) traditional birth attendants amongst the Zulus at least, have no or little knowledge concerning the dangers of antepartum or postpartum haemorrhage, and oedema, convulsions, weakness, dyspnoea or vomiting during pregnancy. They also do not recognise early rupture of membranes as a warning sign. They traditionally are not concerned with meconium in the liquor amnii, possibly because this would be difficult to recognise on the dung floor of a dimly lit birth hut. Lack of knowledge about these aspects of delivery possibly accounts for the high perinatal mortality rate amongst home births as compared to hospital deliveries (Larsen and van Middelhoop, 1982).

Stillbirths and miscarriages are not readily publicised because of the belief that adultery or forbidden practices may have been responsible (Freedman, 1972).

Accurate comparative figures of stillbirths or rates of miscarriage in hospital or clinic and rural birth situations are not available in consequence.

\section{Related practices}

Coitus after childbirth is traditionally not permitted until after the menses return or until the child is weaned (Freedman, 1972). In fact the post-partum woman is isolated from all, except trusted women, largely because her blood 'defiles'. It is particularly able to weaken men and subject them to danger. The result of these prohibitions coupled with polygamy in some cultures (Pedi, Swazi and Venda) is a natural spacing of children (Freedman, 1972). After an abortion, coitus is permitted once menstruation occurs. Coitus is not permitted by most tribal groups during menstruation (Freedman, 1972) due to the high values placed on purity in most cultures and the association of menstrual blood with impurity. Considering that coitus during menstruation has been related to endometriosis (Freedman, 1972) this practice is again beneficial in the eyes of Western medicine.

Traditional Black birth practices appear to reflect a mixture of physical and spiritual activities. While some practices e.g. dietary restrictions during pregnancy and the position adopted for the delivery have direct physical implications for maternal-infant wellbeing, other practices seem to relate more to appeasing the spirits which control and guide birth for example, the burial of placental and birth products to avoid sorcery (Brindley, 1983), and the wearing of ankle, wrist, neck or abdomen strings to prevent harmful spirits from entering the body (Mazibuko, 1985).

\section{Culture in transition: the rural to urban} migration

While rural birth practices have been documented to some extent (Brindley, 1983; Gumede, 1978; Larsen et al., 1983) little is known about how these have been modified in the process of moving towards high technology medical approaches. 
While rural births continue to take place, more and more Blacks are giving birth in hospitals and clinics in both urban and rural environments (Brindley, 1985a; Griffiths, 1981). The birth practices followed in these hospitals and clinics are based on high technology medicine which includes an emphasis on ante-natal care for the mother, delivery in a supine position with the aid of standard medical interventions whenever appropriate, and post partum care of mother and infant. Deliveries are conducted by Doctors or midwives and no family support is available for the mother during delivery. Traditional practices such as the burial of the placenta or membranes are not usually permitted.

No distinctions in treatment are made between the numerous tribal groups delivering in the hospitals or clinics. While time spent in hospitals is usually shorter post-natally than in white hospitals (due to the practical problem of space shortages to cope with the high volume of patients) technology available or applied is in most cases similar in black and white urban hospitals. Obstetric care in hospitals is usually fairly strongly oriented towards high technology interventions as in the U.S.A. (Chalmers, 1982). Clinics, however tend to use a lower rate of interventions due to the lower need for them (complicated cases are referred to hospitals) and to the lack of available sophisticated equipment.

Comparisons of complications arising in hospital/clinic deliveries as compared to rural births are not readily available. However, research has suggested that in particular perinatal mortality rates may differ by as much as from $30 / 1000$ births (hospital/clinic deliveries) to $135 / 1000$ (home deliveries) (Larsen and van

Middelkoop, 1982).

Partially in consequence of the changed approach to childbirth experienced by Black women today, preparation for this is limited. Traditional forms of preparation for childbirth in the rural fashion were provided by initiation schools (Becker, 1979; Freedman, 1972, Netso, 1977) and the guidance of older girls in the society (Mazibuko, 1985). Today, however these schools are not conducted as frequently as in the past, particularly in the urban areas. In addition, knowledge of Western medical approaches to birth is probably not readily available in the women who conduct these initiation schools or the older girls of the clan. Hence, whatever training for childbirth is given is quite probably not related to the technological approach that will be experienced by many Black women.

Other sources of preparation for Western birth, traditionally used by White women in Southern Africa, are books, magazines or pamphlets (Chalmers, 1984). As these are not available in African languages even this source of information is unobtainable for the Black woman. It is not known as to what use is made of such sources amongst those Black women who are fluent in the language of these books (predominantly English).

It seems as though little knowledge of
Western birth procedures is consequently available for the Black woman delivering in hospitals or clinics today. To ascertain the validity of this assumption a detailed interview protocol was drawn up to assess the attitudes and knowledge of pregnancy, birth and post-natal practices that occur in hospitals and clinics, amongst rural and urban Pedi women. The content of the interview protocol is described in detail in this paper. Analyses of the findings of this interview protocol are summarized briefly here and published in more detail elsewhere (Chalmers, 1987a, b, c, d).

\section{Practical issues affecting the}

\section{methodological approach adopted}

Initially it was hoped that free-flowing interviews with Black women could be conducted, in which any and all areas of interest could be explored fully. For a number of practical reasons this approach proved to be unfeasible.

For instance, the interviewers employed to conduct interviews found an open-ended structure too difficult to implement. Two interviewers were utilized, one in the urban area and one in the rural area. Both women were retired midwives from Baragwanath Hospital (a large provincial hospital on the outskirts of Johannesburg) who had each spent more than 20 years practising midwifery at this hospital. Both women were fluent in Northern Sotho and the rural interviewer was of Pedi origin. The urban interviewer was of the Southern Sotho group. Both women were 'postmenopausal' which proved to be of invaluable aid in the eliciting of responses. Many answers to more intimate questions would probably have been withheld if younger interviewers had been employed. Post menopausal women are regarded as pure and consequently not so likely to resort to witchcraft using the information revealed (Brindley, 1985b). Tribal customs traditionally prohibit the free discussion of intimate or sexual activities particularly amongst the young (Netso, 1977).

Associated with their post-menopausal status was the interviewers' own high standing in their respective communities (Brindley, 1985). This seniority proved important in obtaining the cooperation of women to be interviewed. On a number of occasions women agreed to participate in the study because the esteemed family connections of the interviewers lent credence to the study. On the whole though, women participated readily. Only two women out of the 173 approached refused to participate.

Both interviewers, although highly trained and extremely competent individuals expressed unwillingness and inability to conduct open-ended free flowing interviews with women. Both requested that structured guidance for the interviews be given. Consequently, a modification of the unstructured interview approach had to be adopted.

Based on numerous interviews with Black midwives, White obstetricians employed in Black obstetric hospital units, and Black women and researchers working in the area of Black childbirth experiences, a detailed interview protocol was developed. Contributing to this also, was research based on White experiences of childbirth in hospital and home situations. Resources were examined in depth as to their knowledge of past and present Black birth experiences. The final protocols were also given to some of these resource personnel (Black midwives, White-hospital personnel in Black hospitals) for approval before use.

The interview protocol was divided into two, one for use with women ante-natally and one for use post-natally (Footnote 1). Women were interviewed with either the ante- or the post-natal protocol as was appropriate. Both interview schedules contained approximately 170 questions each and interviews took between $11 / 2$ to $2 \frac{1}{2}$ hours to conduct. Although a structured approach was used with predominantly closed-ended questions, some were open-ended (e.g. 'describe ...', or 'give details ...'). Interviewers were carefully trained on the use of the interview protocol and were encouraged elicit open-ended responses whenever possible. Such responses were freely transcribed and were used for anecdotal analysis only. Although the interview protocols were in English, the interviewers were required to ask the questions in Northern Sotho and to record the answers in English. This approach has been successfully adopted by Craig and Albino (1983). As with the Craig and Albino study, care was taken to ensure that the interviewers understood the English questions. They were instructed to convey the meaning of the questions to their subjects rather than to use a direct translation. The interviewers were allowed little or no leeway however, in transcribing, interpreting or recording the material obtained. In most cases subjects' responses were written down verbatim.

Whenever possible, tape recordings were made of the interviews. These tape recordings were checked against the completed interview schedule for errors of interpretation, translation or documentation of responses by an independent, Northern Sotho speaking social work graduate. Practical problems with the use of the tape recorder by the interviewers (e.g. difficulty inserting casettes or changing batteries) were frequently encountered prohibiting the recording of many interviews. However, 41 interviews were taped. The number of errors recorded on these interviews was 51 resulting in a $0,73 \%$ error rate.

\section{Format of the interview schedules}

Questions on the two interview protocols were not rigidly categorized into sections applicable to pregnancy, or birth or infant care etc. Rather, items relating to the different topics explored were often intermingled with each other. This was done to promote a free flow of ideas on behalf of the interviewee.

On the whole, though, items were ordered chronologically. In addition, items of a non-personal, non-threatening nature were asked initially. Items regarding issues 
relating to sexual activities or attitudes to abortion for example, were included well into the later parts of the interviews.

Interviewers were also instructed to allow the women to talk freely if they wanted to and to insert information revealed in these free flowing sections in the relevant part of the interview schedule. It was hoped, in this way, to approximate opportunities for free flowing 'interviews' to occur at times. In most instances the degree of trust and willingness to talk freely seemed evident. Interviewers reported very few cases of 'difficult' interviewees.

The objective of this research project was to design an interview protocol that would stimulate as much information as possible regarding the knowledge, beliefs and attitudes of pregnancy, birth and early infant care in rural and urban Pedi women.

\section{Content of the interviews}

e two interview protocols developed ante- and post-natal interview schedules) covered somewhat different topics and will consequently be discussed separately. Common to both, however, were the biographical details were were obtained from subjects. These included questions covering previous medical or obstetric history, marital status (accepting traditional marriage rites, e.g. 'lobola' as equivalent of Western marriage rites), educational standard, occupation and income of the interviewee and her partner, housing conditions and availability of appliances such as a fridge, a stove or running water (necessary components for adequate bottle feeding).

\section{The ante-natal interview schedule}

Areas covered by this protocol covered such topics as: knowledge of conception, pregnancy and labour and beliefs and

meditions surrounding these; experiences farding ante-natal care; attitudes to baby care and infant feeding; family influences on the experience of pregnancy or birth, and in particular the role of the husband, economic issues of relevance and attitudes towards hospital/medical care. Each of these are discussed in more detail below.

\section{Knowledge of conception}

Questions were asked relating to the use of contraceptives before the current pregnancy, and reasons for conception. The women's knowledge of the relationship between the stages of the menstrual cycle and conception was also explored. The opportunity for disclosing uses of traditional methods of avoiding conception or encouraging fertility was also offered. Beliefs regarding 'who is to blame' for infertility were explored.

Knowledge regarding the relationship of sexual activity to conception was examined as well as the relationship of intercourse as opposed to sexual play without penetration (a traditional form of contraception according to Craig and Richter Strydom (1983); Freedman (1972) and Moeno (1977)) to conception. How knowledge of conception was obtained was also investigated.

\section{Knowledge about pregnancy}

Awareness of many facets of pregnancy

was explored. Examples of such issues are

- the nature of the foetus as a "collection of cells that don't look like a baby at all, but later change' as opposed to a 'small child who gets bigger'.

- the ability to determine the sex of the foetus, or to influence its sex.

- dietary taboos and knowledge of beneficial dietary habits.

- practical issues such as attending antenatal care, or intercourse during pregnancy.

- sources of knowlcdge about pregnancy and infant care.

- knowledge of some common medical interventions employed during labour e.g. caesareans, forceps, epidurals, episiotomies, vacuum extractions, inductions.

- knowledge about infant feeding, e.g. the value of colostrum and breast or bottle feeding practices and problems.

- knowledge of traditional customs such as placental burial, the meaning of intact membranes at birth, and disposal of the cord.

\section{Attitudes}

Attitudes regarding many aspects of the pregnancy and birth experience were explored including, amongst others, attitudes to the pregnancy itself; to antenatal care; to the place of delivery; to previous obstetric experiences; to infant feeding practices; to birth attendants (Western or traditional); to medical interventions in labour; to abortion; to pain relief in labour; to maternal birth position; to social support in labour and to books as a source of information about pregnancy and birth.

\section{Social influences}

Social influences on the mother's experiences of pregnancy and birth that were explored included the role of the husband; the woman's family and in particular her mother and sisters; the hospital personnel and economic issues. Of the latter, the mother's occupational behaviour formed the bulk of the issues explored.

\section{The post-natal interview schedule}

As the post-natal interview schedule was designed for a different sample from the ante-natal interview sample (for practical reasons) some items included in it were similar to those used in the ante-natal schedule. In particular areas of research common to both questionnaires were those described as 'Biographical details' above. Other areas explored by this protocol were: reactions to labour; attitudes and practices regarding baby care and infant feeding; contraceptive practice and knowledge; practical problems in the early months of parenthood, sources of social support and economic considerations. These are described more fully below.

\section{Reactions to labour}

Included in this category were questions relating to the birth experiences of the mother and her understanding of and reaction to these; the presence of birth attendants and the desire for alternative sources of social support at this time; attitudes to pain relief; the delivery position desired; knowledge of traditional beliefs as well as of technological approaches to birth experiences; and reactions to immediate post birth practices regarding mother-infant contact and feeding experiences.

\section{Baby care and feeding}

Much of the post-partum questionnaire was devoted to infant feeding practices. Areas explored in this regard were timing of the first post-natal feed; attitudes to colostrum; practices regarding bottle feeding either totally or in part while in hospital/clinic or after discharge and problems associated with these; practical problems regarding breast feeding and knowledge of how to handle them, such as cracked nipples, engorgement, or 'too little milk'; timing of such breast or bottle feeding problems; reasons for not breast feeding at all, or for weaning from breast to bottle; infant feeding practices following weaning; sources of advice regarding breast or bottle feeding and the possible influences of infant feed advertising; attitudes regarding the relationship between feeding practices and ill health in the baby; attitudes to demand or routine feeding; beliefs and attitudes regarding the influences on, and of, breast or bottle feeding.

In addition to infant feeding practices, practical problems relating to other aspects of baby care were covered by the interview schedule including such items as difficulties with bathing babies, nappy changes, care of other children, or other family members, emotional difficulties and financial cares. Sources of help with these areas of difficulty were also explored.

\section{Contraceptive practices}

The use of contraceptives following birth was explored. Of particular interest was the attitude towards breast feeding as an adequate contraceptive as well as restrictions regarding breast feeding and intercourse.

\section{Economic considerations}

This section explored occupational behaviours and practices following delivery. Issues such as the feasibility of breast feeding and working simultaneously were explored. Attitudes towards such an idea were examined. The availability of child caretakers other than the mother was also investigated.

\section{Summary of findings}

The data obtained is far too vast to be described in detail in a single paper. In depth analyses of the various issues examined have been reported elsewhere (Chalmers, 1987, a; b; c; d). The present paper however, provides an overview of 
major findings in the various areas of investigation.

\section{Biographical details of the sample}

In all, 171 Pedi women were interviewed. Of these 89 were interviewed ante-natally and 82 post-natally. Approximately equal numbers of these women delivered in urban or rural, hospital or clinic environments (Urban hospital $\mathbf{N}=45$; Urban clinic $\mathrm{N}=42$; Rural hospital $\mathrm{N}=$ 37; Rural clinic $\mathrm{N}=47$ ). Ante-natal interviews were conducted in the hospital or clinic environs while post-natal interviews were conducted at home. Names of all Pedi women delivering in the hospitals or clinics during the period of study were obtained and interviewers were, in most cases, able to follow these up. Interviews were continued until the desired number of subjects in each group had been obtained.

Of the total sample $52,6 \%(90)$ were married by Western or tribal custom; $39,7 \%(68)$ had never been married and were living with their parents; $5,8 \%(10)$ had never been married but were living with their partners and $1,8 \%$ (3) were divorced.

The standard of education of mothers was fairly widespread with $8,8 \%$ (15) having no education or only the first two years of school completed. Twenty $(11,7 \%)$ had had between 2 and 6 years of schooling, 32,2\% (55) had obtained either 7 or 8 years of schooling while a further $42,7 \%$ (73) had completed between 9 and 12 years of schooling. Only 4,1\% (7) had obtained some form of post school qualification.

The majority of the sample were unemployed prior to falling pregnant $(65,5 \%, N=112)$. Of those who did work, the majority $(42,4 \%, N=25)$ were employed in domestic work. Some few were employed in professional occupations such as teaching or nursing $(20,3 \%, \mathrm{~N}=$ 12) while the remainder were employed in clerical $(6,8 \%, \mathrm{~N}=4)$ sales $(11,9 \%, \mathrm{~N}=7)$ or factory $(5,1 \%, N=3)$ positions. The mean salary of the total sample was R 160,28 per month ( Range $=$ R22 - R992).

The mean age of the sample was 27,6 with ages ranging from 16 to 44 . The mean number of children per woman was 1,75 with a range of 0 (primiparaes) to 10. There were $59(34,5 \%)$ primiparaes included in the study while $10(11,2 \%)$ of the women had five or more children at the time of testing.

\section{Results}

For convenience, figures included in the text have been incorporated in Table 1.

This table gives the percentage response to some questions as well as whether information on that question was obtained from ante- or post-natal interviews, or both. Because of the vast quantity of data obtained, many categories of response that were included in answers to these questions have been omitted. In addition, not all the questions asked are included. Only major issues of relevance to the introductory section are made available here.
TABLE I. PERCENTAGE RESPONSES TO SOME MAJOR ISSUES IN ANTEAND POST-NATAL WOMEN

Question asked

Percentage responses

About Conception

How are babies conceived?

Through intercourse $\quad 77,5$

Without penetration $\quad 11,2$

What is the baby like in early stages of development?

A collection of cells that change and develop $\quad 79,8$

Don't know 16,9

From whom did you learn about conception?

Traditional teacher

Self taught through reading etc.

Mother

$\mathbf{N}=\mathbf{8 9}$

$\mathbf{N}=\mathbf{8 2}$

hen can you fall pregnant?

While menstruating

Any time you're not bleeding

Two weeks before period starts

Two weeks after bleeding starts

58,4

22,5

8,9

10,1

39,3

28,1

32,6

Signs of conception

Cessation of menstruation

Stomach enlargement

Confirmed by a doctor

Dreams

Was this pregnancy planned? Yes

Are you happy about being pregnant? Yes

Did you use contraception? Yes

What contraceptive? Pill

Injection

IUD

53,7

88,8

38,2

20,2

14,6

11,2

Who taught you about pregnancy?

Nurse

77,5

Your mother

30,3

Traditional healer

Should you reveal your pregnancy to others? Yes

Who can you tell?

Other family 22,8

Friends

Did you attend ante-natal clinics?

Do you know what the following are?

$\begin{array}{ll}\text { Caesarean section } & - \text { No } \\ \text { Forceps } & - \text { No. } \\ \text { Vacuum extraction } & - \text { No } \\ \text { Induction } & - \text { No } \\ \text { Episiotomy } & - \text { No }\end{array}$

Should the placenta be buried?: Yes

Should the blood of birth be buried?: Yes

Is 'Isihlambezo' good in pregnancy?: Yes

Preference for place of delivery

Home

Clinic

Hospital

4,9

28,0

64,6

Preference for position of delivery

Lying flat on bed

Kneeling or squatting

75,3

86,5

96,6

96,6

73

1,1

4,5

36,0
59,6

91,0

1,1

Who would you like with you at delivery?

Husband

30,5

Mother

19,5

Who will teach you about baby care?

Nurses

77,5

Your mother

30,3

Sisters

21,4

Do you want to (or are you)

breast feed(ing)?

bottle feed(ing)?

mixed breast and bottle feed(ing)?

67,1

11,4

21,6

70,7

3,7

Is colostrum good for the baby?
Yes
48,3
No
27,0
Don't know 
What problems did you experience post-natally?

Engorgement

Depression

Did you routine feed your baby?

Did you demand feed your baby?

Is it better to routine feed? Yes

Do you have access to a fridge? Yes

Do you have access to a stove? Y'es

Do you have access to running water? Yes

What was your last salary? $\mathrm{x}=$
Not enough milk

Cracked nipples

\begin{tabular}{cc} 
& 36,6 \\
& 17,1 \\
& 6,1 \\
& 4,9 \\
& 45,1 \\
& 52,4 \\
& 79,3 \\
& 23,2 \\
18,0 & 58,5 \\
58,4 & 86,6 \\
84,27 & 126,306 \\
194,25 & \\
\hline
\end{tabular}

\section{Conception}

The majority of the ante-natal women appeared to be aware of how conception takes place although some striking misconceptions regarding conception mishout penetration, and timing of iception seemed evident (Table 1). Of most interest with regard to conception was the high proportion of women who learned about conception from traditional teachers $(58,4 \%)$. Also interesting was the number of women who were self taught i.e. from reading $(22,5 \%)$. The lack of information giving performed by the woman's own mother is also striking $(8,9 \%)$.

The most frequently reported signs of conception were cessation of menstruation $(96,6 \%)$ and stomach enlargement $(96,6 \%)$. $A$ high proportion of women also used medical examinations for confirmation of pregnancy $(78,7 \%)$. Only $52,8 \%$ of women reported dreams as indicators of pregnancy. The mean stage at which women reported knowing they were pregnant was 2,1 months.

In $54 \%$ of the women, the pregnancy was planned, although $88 \%$ reported being py about their pregnancies. Of the e-natal sample, $38,2 \%$ reported falling pregnant while using contraceptives. The most popular contraceptives were the pill $(20,2 \%)$, the three monthly injection $(14,6 \%)$ and IUD's $(11,2 \%)$.

\section{Pregnancy}

Women reported learning about pregnancy itself largely from nurses $(77,5 \%$ - antenatal sample). The next most important source of information in this regard was the woman's mother $(30,3 \%)$. Only $7,7 \%$ reported learning about pregnancy from traditional teachers.

The majority of ante-natal women believed that pregnancy must be kept secret. Only $29,2 \%$ said that their pregnancy could be revealed to others. Those that did reveal their pregnancies did so to close family members, e.g. their mother $(22,8 \%)$ while a few $(7,9 \%)$ told friends.

The majority of the total sample attended ante-natal clinics $(96,5 \%)$. However, it appeared that such clinics were predominantly aimed at physical well being of the mother and baby, with very little information about birth possibilities being given. For instance the majority of the ante-natal sample did not know what various birth procedures meant: caesarean section $(75,3 \%)$; forceps $(86,5 \%)$; vacuum extraction $(96,6 \%)$; induction $(96,6 \%)$; episiotomy (73\%). (In asking questions about these techniques technical terms were avoided as far as possible so that the words used by the mothers themselves for these techniques were always utilized, e.g. episiotomy = cut to bottom or lower parts; caesarean section $=$ cut mother's tummy to take baby out, etc).

Knowledge about traditional birth practices seemed to be equally lacking. For instance only $1,1 \%$ of ante-natal mothers believed that either the placenta or the blood of childbirth should be buried. About $16 \%$ of ante-natal mothers did, however, report that blood lost during childbirth is special, but did not know in what way. 'Isihlambezo' was in general not favoured by the women.

However, the vast majority of ante-natal women wished to adopt a supine position for delivery $(91 \%)$. The major reason given for this was so that the staff could observe what was happening $(48,3 \%)$.

Preferences in both ante- $(89,6 \%)$ and post-natal $(64,6 \%)$ groups was for a hospital delivery. Less than $5 \%$ in both groups would have preferred a home delivery. Only about a third of the sample would have liked their husbands with them at delivery, while more would have valued his presence after birth.

\section{The post-partum period and infant care}

As with knowledge about pregnancy, the major source of knowledge anticipated by ante-natal women was nurses $(77,5 \%)$ with the woman's mother being looked to for such information as well $(30,3 \%)$.

Most women wanted to (ante-natally) or were actually (post-natally) breast feeding. Expected and actual figures in the two groups with regard to bottle and mixed feeding preferences also appeared to be similar (Table 1). Less than half the antenatal women believed that colostrum was good for the baby $(48,3 \%)$. About $45 \%$ of mothers were 'routine feeding' their babies, and $53 \%$ 'demand feeding'. However, $79 \%$ of the sample thought routine feeding was the method of choice.

Few problems were reported in the postpartum period (Table 1). Only engorgement offered a problem to about one third of the post-natal sample.

Help in the post-natal period was offered largely by the woman's mother, particularly for help with nappy changing $(40,2 \%)$; baby bathing $(35,4 \%)$ and with other children $(23,2 \%)$. Husbands helped less than $2 \%$ of mothers for all chores except with the mothers' own feelings of adjustment $(23,2 \%)$ and with financial assistance $(48,8 \%)$.

The majority of the mothers intended caring for their babies themselves $(92,1 \%)$. However, at least half the post-partum sample believed that a mother should work after having a baby $(51,2 \%)$. Many mothers however, reported that jobs which allow for baby care and employment simultaneously are difficult to find $(37,8 \%)$.

\section{Discussion}

The overriding trend which appears evident from the brief summary of some major findings of this study is the move away from traditional tribal birth customs towards a highly technological birthing process. Evidence for this comes from the lack of knowledge about traditional customs regarding, e.g. the handling of the placenta and blood of childbirth; the desire for hospital births in a supine position; the lack of desire for assistance or teaching about pregnancy, birth or the post-natal period from traditional birth attendants; and the increasing dependence on nurses and ante-natal clinics for information and assistance during this period.

Some customs which seem to be resistant to this trend are the persistent desire to exclude the husband from labour, the need to maintain secrecy about pregnancy for fear of bewitchment and the reasonably high rate of breast feeding in the sample.

\section{Implications}

The apparent move towards technological births may well be a mixed blessing in the sample studied. While health of infant and mother has benefited from this trend in places where it has occurred in terms at least, of lowered infant maternal mortality rates (Larsen and van Middelkoop, 1982) some major benefits of the traditional birth procedure are being lost.

For instance traditional sources of knowledge and preparation for childbirth and parenthood are no longer being sought. However it appears unlikely that these have been replaced to any great extent by the technologically oriented hospitals and clinics as yet. (See findings regarding knowledge of birth techniques Table 1). And yet, mothers are looking, in particular to nurses, to fill this gap.

In addition, much moral and social support given to mothers in a traditional birth situation is not available in hospitals and clinics. Excluding the father from a hospital or clinic delivery as is the custom does not appear to present a problem for the sample studied. However, excluding the woman's mother in the hospital/clinic situation as well as other women who may have attended the birth in the traditional 
situation (Brindley, 1985a) deprives the mother of her warm, supportive, familia environment for birth. It is extremely unlikely that this support is provided by the nurses or doctors who are usually under extreme work pressures.

Childbirth and parenthood in the traditional environment are viewed as an ongoing continuous process in that preparation for this starts early in life, (at initiation schools for instance (Mazibuko, 1985)) and is continued through close supervision of the pregnant or new mother by trusted elders (Brindley, 1985a). In addition, in keeping with the Black philosophy of health and illness, the physical aspects of birthing are continually integrated with the spiritual, social and behavioural.

In a high technology system, however, this integration of functioning is lost. Instead, as with the rest of man's healing services, the pregnant woman or new mother is being forced to seek various, often unrelated, sources for assistance at each stage of the process. For instance she seeks ante-natal care from strangers whose teachings can only be different from her own family's past experiences. She is delivered by a new set of strangers unrelated to the first and has no contact with her trusted, familial, support systems. After birth she is returned home again to seek advice from those whose experiences may be different from what she has been taught in the clinics or hospitals. In essence, the traditional integrated transition to parenthood has become, as it is for Whites in South Africa, a disjointed experience.

Her home environment may also make it extremely difficult for her to observe the rules of hygiene she has been taught regarding, for instance, adequate bottle feeding practices. Access to fridges for storage of prepared bottles is limited: only $20,6 \%$ of the sample studied had such facilities (Table 1). Only a little over half the sample studied had access to a stove $(58,5 \%)$ while most but not all had running water $(85,5 \%)$ (Table 1). Given such reality, all ideals of healthy bottle feeding practices must be overlooked in many instances.

Given the, in many instances, inadequte facilities for good bottle feeding, breast feeding needs to be strongly encouraged. Financial considerations also lend weight to the value of breast feeding in the sample studied ( $\overline{\mathrm{X}}$ last salary earned $=\mathrm{R} 160,28$ per month, $\mathrm{N}=81$ ) (Table 1 ). It can only be hoped that in this regard the trend to follow 'White' patterns of feeding in South Africa does not occur. Black perceptions of White and Black breast feeding patterns in the present study indicated that while $67 \%$ of the post-natal sample believed that all Black women breast fed their babies, none of the sample thought all White women did the same.

A number of alternatives to the preparation and training of Black women with regard to the 'childbirth experience' exist. Most of these are determined by the opportunities and limitations of the environment - rural/urban - that prevails. Some of these possibilities include:

- training women within the confines of the hospital or clinic (as is done for White women and some Blacks). This training needs to be integrated with the values of the community such as their desire for secrecy/privacy regarding their pregnancy experiences.

- training women through community health workers who can take the 'required' knowledge into the homes of the women. Perhaps worthy of consideration is encouraging retired midwives or currently unemployed, but skilled (in this field) workers to apply their knowledge to their communities. In this way the family unit can be prepared for the type of birth to be experienced, and not just the woman herself.

- working more closely with traditional birth attendants to integrate the desirable aspects of high-technology medical knowledge with traditional birth practices. Most of the documents which describe where this approach has been tried have reported success (Larson et al, 1983; 1983b; Leedam, 1985; Staugard, 1981). In addition such an approach would be in accordance with the World Health Organizations' Seventh Programme of Work (1982).

- working more closely with the instructors who run initiation schools so as to provide a realistic expectation of birth and early parenthood in a clinic or hospital setting.

- working more closely with and educating the grandmothers who in so many instances still dominate the early years of child-rearing. In particular, with regard to infant care, more attention needs to be directed to the grandmother, in addition to the mother, than has hitherto been the case.

The problems facing those concerned with the implementation of adequate health care facilities throughout South Africa, are numerous. It has long been apparent that alternatives to hospital intensive medical approaches have to be explored. The area of education for childbirth and parenthood appears to be no exception.

\section{FOOTNOTE}

1. Copies of the interview protocols are obtainable from the author.

\section{REFERENCES}

1. Barker, E.A. 1973. Traditional African views on health and disease. The Central African Journal of Medicine, no. 19: 80-82.

2. Becker, P. 1979. From tribal days to city ways. South African Sugar Journal no. 63: 185-187.

3. Brindley, M. 1983. The role of old women in Zulu culture. Unpublished doctora! dissertation submitted to the University of Zululand.

4. Brindley, M. 1985a. Old women in Zulu culture: The old woman and childbirth. South African Journal of Ethology, no. 8: 98-108.

5. Brindley, M. 1985b. Traditional Zulu childbirth. Paper presented to the First
Congress of the Association for Childbirth and Parenthood, Johannesburg, November.

6. Chalmers, B. 1982. Psychological aspects of pregnancy: Some thoughts for the eighties. Social Science and Medicine, no. 16: 323-331.

7. Chalmers, B. 1984. Early Parenthood: Heaven or Hell. Cape Town: Jutas.

8. Chalmers, B. 1987a. Changing views regarding some delivery customs amongst Pedi women. South African Medical Journal, no. 72: 137-138.

9. Chalmers, B. 1987b. Pregnancy: The Pedi woman's veil of secrecy. South African Journal of Psychology, no. 17 (1): 30-31

10. Chalmers, B. $1987 \mathrm{c}$. The father's role in labour: Views of Pedi women. South African Medical Journal, no, 72: 138-140.

11. Chalmers, B. 1987d. Black women's birth experiences: Changing traditions. Journal of Psychosomatic Obstetrics and Gynaecology, no. 6: 211-224.

12. Cheetham, R.W.S., Griffiths, J.A. 1982. Sickness and medicine - an African paradigm. South African Medical Journal, no. 11: 954-956.

13. Craig, A.P., Albino, R.C. 1983. Urban Zulu mothers' views on the health and health cs of their infants. South African Medical Journal, no. 63: 571-572.

14. Craig, A.P., Richter-Strydom, L.M. 1983. Unplanned pregnancies among urban Zulu schoolgirls. South African Medical Journal, no. 63 : $452-455$.

15. Freedman, R.S. 1972. Aspects of Bantu domestic life in relation to some gynaecological conditions. South African Medical Journal, no. 46: 1383-1386.

16. Gelfand, M. 1977. An African culture in relation to medicine. The Central African Journal of Medicine, no. 23: 15-18

17. Gelfand, M. 1980. African customs in relation to preventive medicine. The Central African Journal of Medicine, no. 27: 1-8.

18. Griffiths, M.C. 1981. A comparison of admissions to a semirural hospital between the years $1959 / 1960$ and $1977 / 1978$. South African Medical Journal, no. 27: 983-986.

19. Gumede, M.V. 1974. Traditions and customs. The Leach, no. 44: 35-38

20. Gumede, M.V. 1978. Traditional Zulu practitioners and obstetric medicine. South African Medical Journal, no. 53: 823-827. 21. Larsen, J.V., van Middelkoop. 1982. The
'unbooked' mother at King Edward VIII Hospital, Durban. South African Medical Journal, no. 62: 483-486.

22. Larsen, J.V., Msane, C.L., Monkhe, M.C 1983. The Zulu traditional birth attendant. South African Medical Journal, no. 63: 540-542.

23. Larsen, J.V., Msane, C.L., Monkhe, M.C 1983b. The fate of women who deliver at home in rural K waZulu. South African Medical Journal, no. 63: 543-545.

24. Leedham, E. 1985. Traditional birth attendants. International Journal of Gynaecology and Obstetrics, no. 23: 249-274.

25. Lipowski, Z.J., Lipsitt, D.R., Whybrow, P.C. 1977. Psychosomatic Medicine. New York: Oxford University Press.

26. Mazibuko, D. 1985. Childbirth in cultural transition. Paper presented to the First Congress of the Association for Childbirth and Parenthood, Johannesburg, November.

27. Manganyi, N.C. 1974. Health and disease. South African Medical Journal, no. 48: 922-924.

28. Mankazana, E.M. 1979. A case for the traditional healer in South Africa. South African Medical Journal, no. 56: 1003-1007.

29. Moeno, N.S. 1977. Illegitimacy in an African urban township in South Africa: An ethnographic note. African Studies 36: 43-47. 
30. Mphahlele, M. 1982. Dietary restriction for the prevention of disproportion and obstructed labour among the Pedis of yesteryear. South African Medical Journal, no. 61: 842.

31. Munyaradzi, O.M. 1975. The African's attitude to disease. The Central African Journal of Medicine, no. 21: 137-139.

32. Netso, B.P. 1977. Sex: Cross-cultural consideration. The Leach, no, 47: 1-2.

33. Ross, S.M., Macpherson, T.A., Naeye, R.L. Khatree, M.H.D., Wallace, J.A. 1982. Causes of fetal and neonatal mortality in a South African Black community. South African Medical Journal, no. 61: 905-908.

34. Seventh General Programme of Work Covering the Period 1984-1989. WHO, Geneva, 1982.
35. Staugard, F. 1981. Traditional medicine in a developing country. Journal of the Medical and Dental Association of Botswana. no. 11: 7-32.

36. Stein, H., Mouton, S.C.E. 1979. Neonatal mortality in a Black urban community. South African Medical Journal, no. 55: 413415.

37. Stewart, K.S., Cowan, D.B., Philpot, R.H. 1979. Pelvic dimensions and the outcome of trial labour in Shona and Zulu primigravidas. South African Medical Journal, no. 55: 847-851.

\section{ACKNOWLEDGEMENT}

The financial assistance of the Human Sciences Research Council (HSRC) is gratefully acknowledged. Opinions expressed are not necessarily those of the HSRC. Thanks are due to Professor Mphahlele, Minister of Health and Welfare, Lebowa; and Doctors Beukes and van den Heever, Superintendents Soweto

Community Health Centres and Baragwanath Hospital, for permission to conduct this study. Thanks are also due to Sisters F. Modise and F. Malatji for conducting interviews and to Mrs D. Koza for checking them.

Professor B Chalmers School of Psychology University of the Witwatersrand 